\title{
Analysis of pressure drop in a numerical simulation of internal nanofluids flow
}

\author{
Marcos Barroso Filho \\ Universidade Federal de Minas Gerais \\ marcosbarrosol@hotmail.com
}

\begin{abstract}
This study aims at the calculation of pressure drop from simulation of internal nanofluid flow in a new and long stainless pipe (1.4 $\mathrm{m}$ long and $0.01 \mathrm{~m}$ diameter). Calculations were made from numeric simulations which were based on theoretical models and experimental proprieties of three nanofluids: graphene nanodiscs with water, titanium oxide nanospheres with water and iron oxide nanospheres with water. Different concentrations were considered in each kind of nanofluid. Calculus of pressure drop were based on Darcy-Weisbach equations model. It was considered a fully developed turbulent flow for two numbers of Reynolds (Re), 4583 and18187. After analysis, it was verified a decrease in pressure drop values for each nanofluid, in parallel with the decrease of particulate quantities
\end{abstract}

Keywords: Nanofluids, Pressure Drop, CFD.

\section{INTRODUCTION}

Every working fluid seen in thermodynamic systems should has certain characteristics to justify its use. Among the main characteristics in rheology, we can quote: thermal conductivity, viscosity and density. Thermal conductivity will influence the amount of heat removed from the process, directly impacting the efficiency system. Viscosity and density have direct impact on pressure drop, generating an "energetic cost" that should be "paid" to pump the fluid. 
Every mix between a base fluid and nanometric particles, in other words, particles smaller than 100 nanometers, is considered a kind of nanofluid. The technological progress has show to the scientific community the possibility to use nanofluids on thermodynamics applications. It was inferred that a given fluid, when added of solid particles with high thermal conductivity, has its thermal mix properties modified improving the fluid thermal efficiency. During the pumping, a part of mechanical energy provide from the pump is transformed in thermal energy due to shear stress forces between fluid and pipe wall. This phenomenon is undesirable, because cause losses of fluid energy and decrease energetic efficiency [1]. This transformation, usually called pressure drop, is a function of some parameters from pumped fluid and pump system. Some parameters of pumping system are height variation, fluid pressure and velocity. The related proprieties from the pump fluid are density and viscosity. Therefore, compare the possible thermal energetic gain against the variation of pressure drop is fundamental to evaluate the total nanofluids efficiency, and compare it with usual fluids. As showed in [2], for the thermophysical proprieties used, gains were not significant from a thermal point of view.

Although all efforts involved in nanofluids studies, the mathematical models used to define thermophysical proprieties are still incipient, consequently there are considerable differences among experimental and theoretical, as showed in academic papers [3] and [2].

In this study, it was evaluated, through numerical simulation, 3 nanofluids flowing over a pipe with 1.4 meters length, for two numbers of Re (4583 e 18187). The get values were compared to pure water on the flow.

\section{METHODOLOGY}

For evaluation of pressure drop, it was selected, from available bibliography provided from [2] , the pipe geometry. The matemathical models for nanofluids thermophysical properties were obtained from [4], [5] and [2]. The properties used were viscosity and density thus, in agreement with 
available mathematical models, they varie with the nanoparticles concentration on the fluid and temperature.

The transitional number of Re from laminar to turbulent flow in a pipe are between Re $2000 \mathrm{e}$ 4000 according to [6]. Nevertheless, there are possibilities for laminar flow with Re above 10.000 [1]. For this study, it was considered turbulent flow for all calculations. The three selected nanofluids were: graphene nanodiscs with water, titanium oxide nanospheres with water (titania) and iron oxide nanospheres with water (magnetite). For each nanofluid, it was evaluated four different concentrations.

For graphene nanofluid, the following mass concentrations were evaluated: $0,025 \%, 0,050 \%$, $0,075 \%$ e $0,1 \%$. For others nanofluids, four concentrations were considered, but in volume: $0,2 \%$, $0,6 \%, 1,0 \%$ e $1,5 \%$. These concentrations were selected like used in [2].

To compare, calculations were made with pure water in the same thermal conditions of the nanofluids. The water and nanofluids thermophysical proprieties were evaluated at $30 \circ \mathrm{C}$. For calculations effect, it was considered smooth pipe, so that, the friction factor $\mathrm{f}$ for Blasius function is only in function of Re number[1].

It was considered a pipeline with 1.4 meters length and 0.1 meters of diameter. The geometry is showed on Fig. 1. The length is more than 10 times bigger than the diameter, for this reason, it was considered a fully developed flow, like suggested on [7]. 
Calculation and figures were made using software Excel[8]. Charts of pressure drop were plotted for each nanofluid concentration for both numbers of Re. Also, pressure drop of pure water in the same conditions was calculated and used to compare efficiency.

Figure 1: Geometry considered

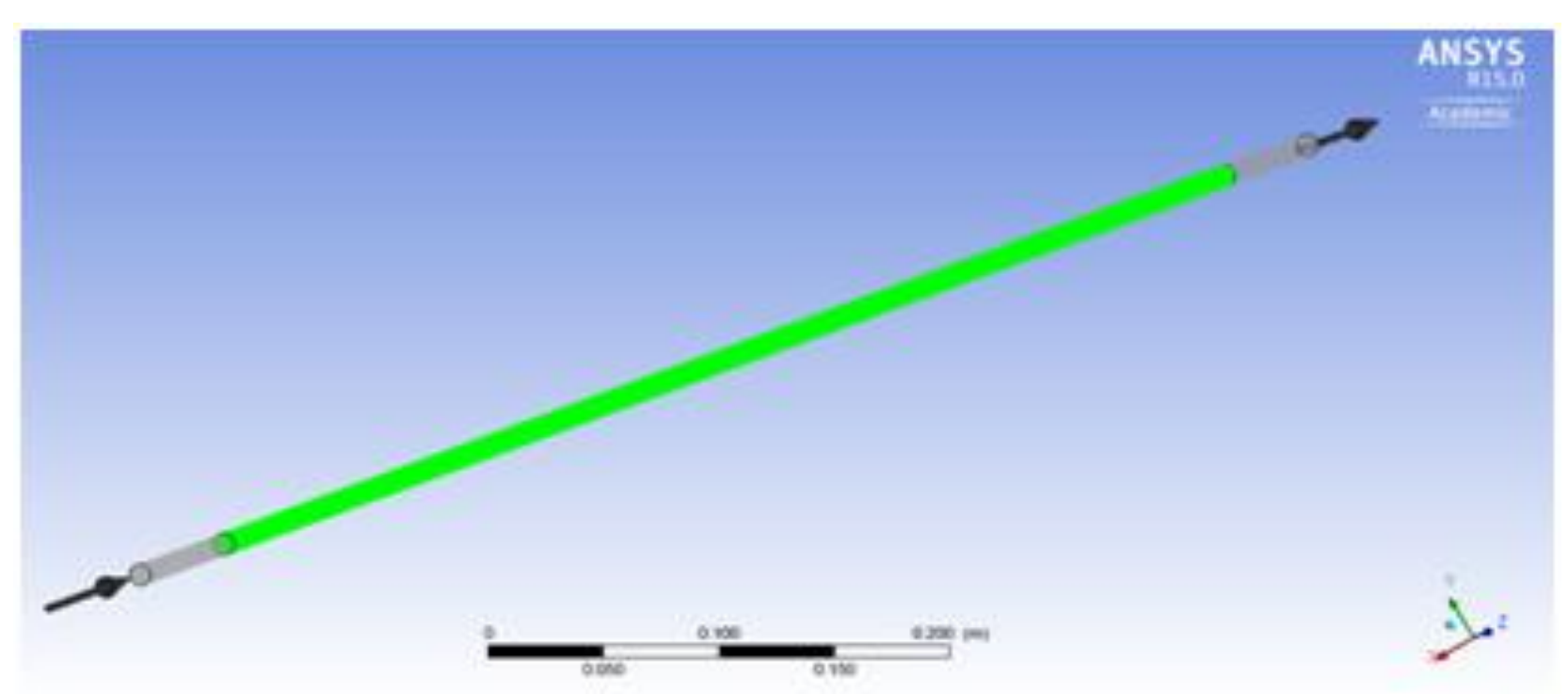




\section{RESULTS}

The results obtained after calculations Are presented in this section. The Fig. 2 shows pressure drop for graphene with the number of Re of 4583. The Fig. 3 also shows results of pressure drop,

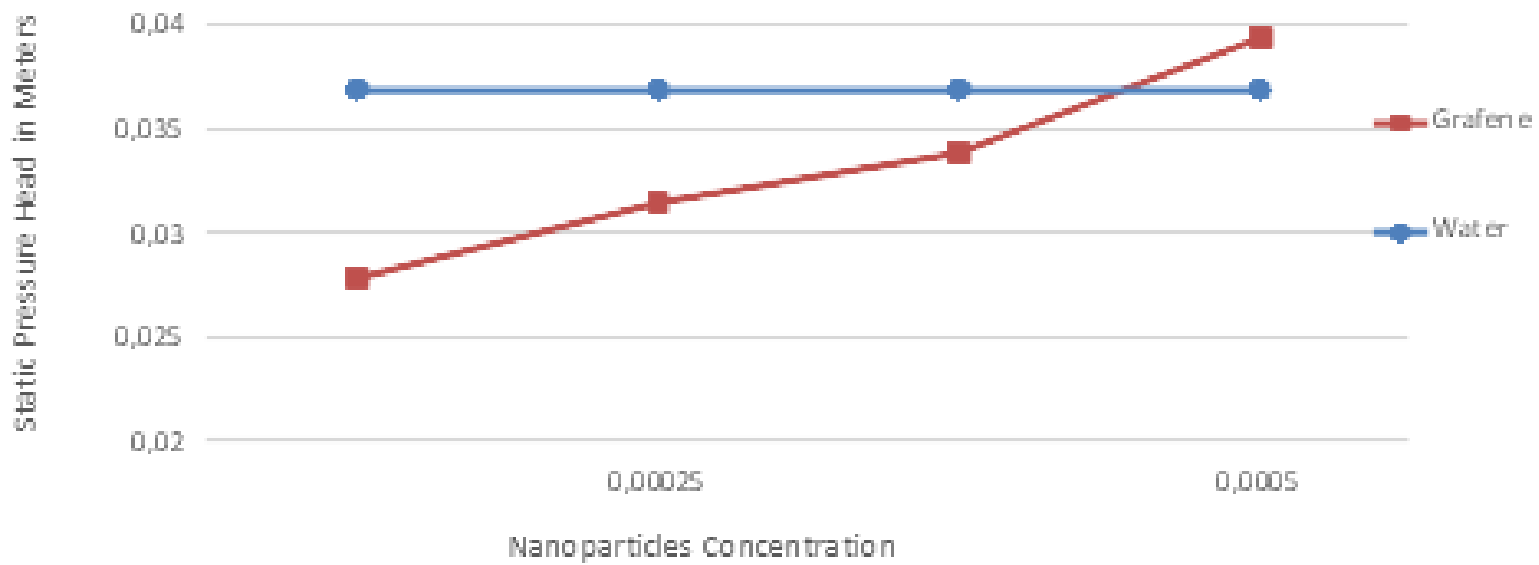

but for titania and magnetite. The values of pressure drop are showed as static pressure head.

Figura 2: Pressure drop of Grafene for Re 4583

All nanofluids showed an increase of drop pressure with an increase of particulate concentration. This fact is in agreement of [4] and [9] data. For Re 4583 flow, titania and magnetite nanofluids presented, for every particulate concentration, a bigger pressure drop than water. Graphene showed a pressure drop bigger than water only in concentrations bigger than $0,085 \%$, as seen in Fig. 2 . The behavior disparity between nanofluids could be caused by the proximity of transitional number of Re, which is between 2000 and 4000 according [6]. However, there may have an imprecision in considering this flow as turbulent with a 4583 Re. This imprecision, and the geometry difference between nanoparticles, could explain the different behavior showed on the chart. 


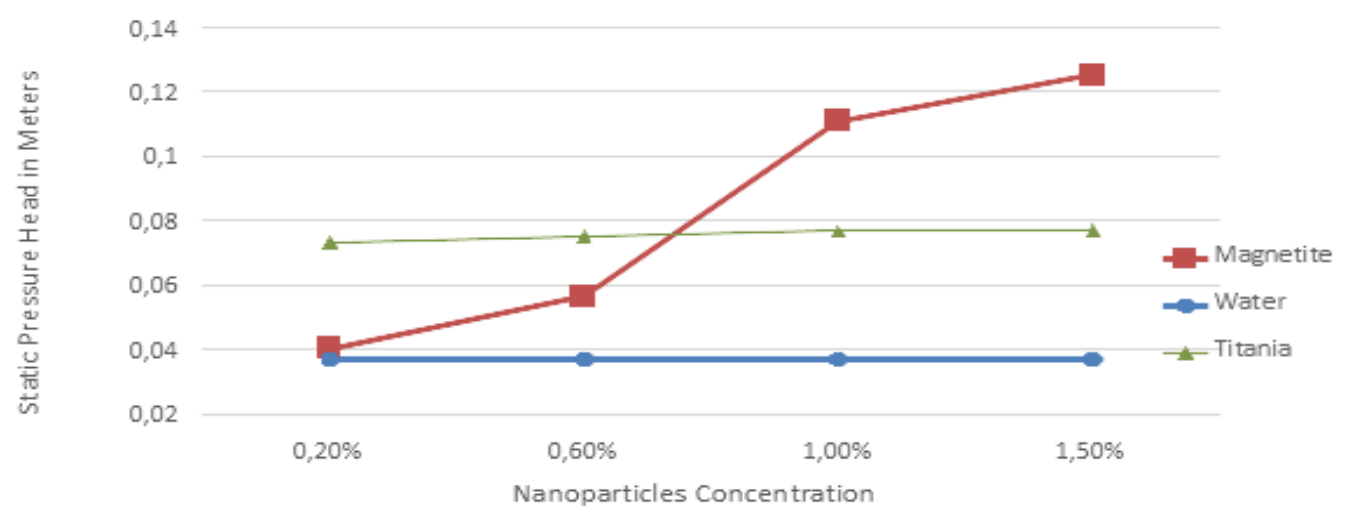

Figura 3: Pressure drop of Magnetite and Titania for Re 4583

The Fig. 4, of ghaphene and the Fig. 5 of titania and magnetite, shows pressure drop for Re number of 18187. Nanofluids presented same behavior at Re 18187, and showed a smaller pressure drop than water in a smaller concentration. In addition, nanofluids present increasing pressure drop along with the increase of concentration. This behavior suggests that the consideration of a fully developed turbulent flow is correct.

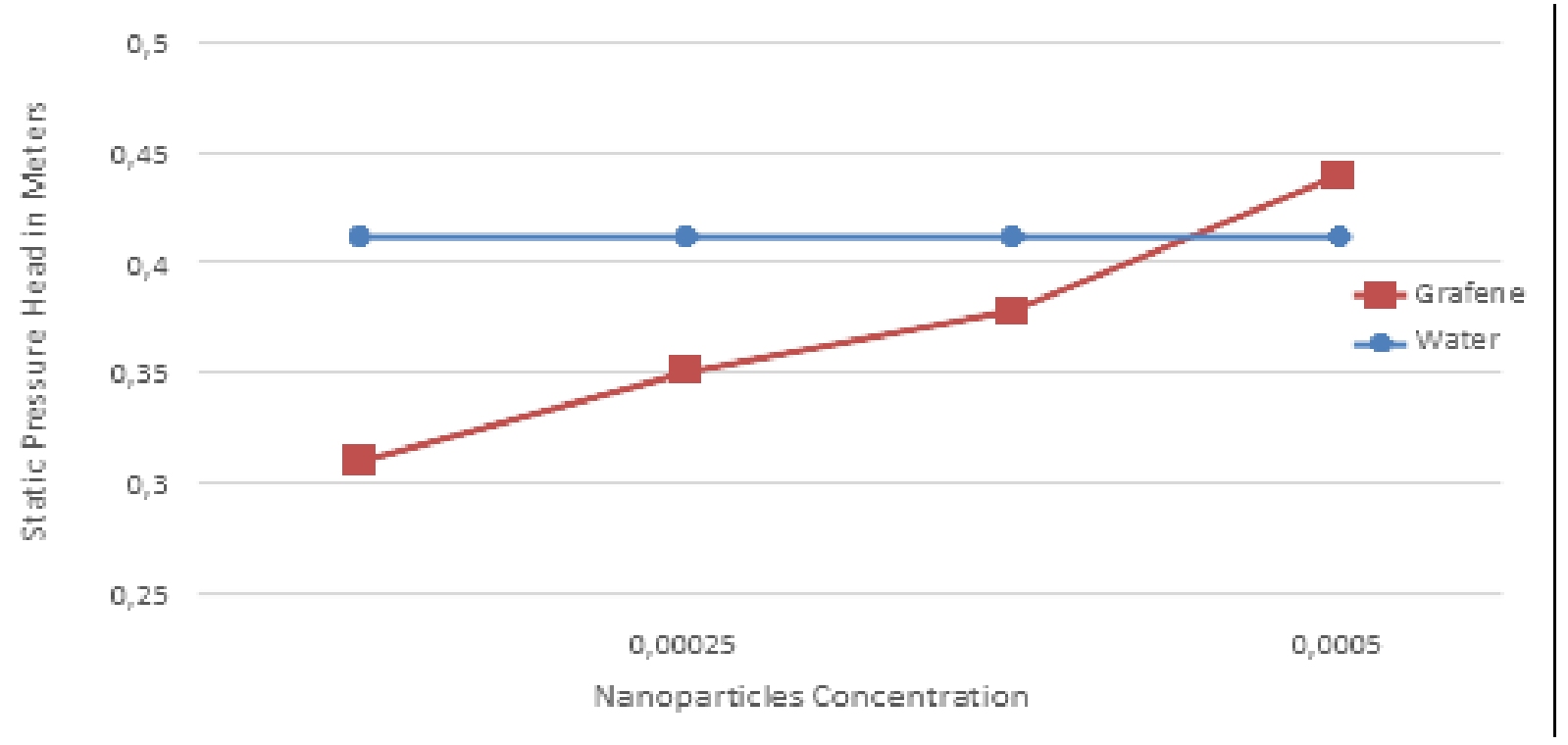

Figura 4: Pressure drop of Grafene for Re 18187 


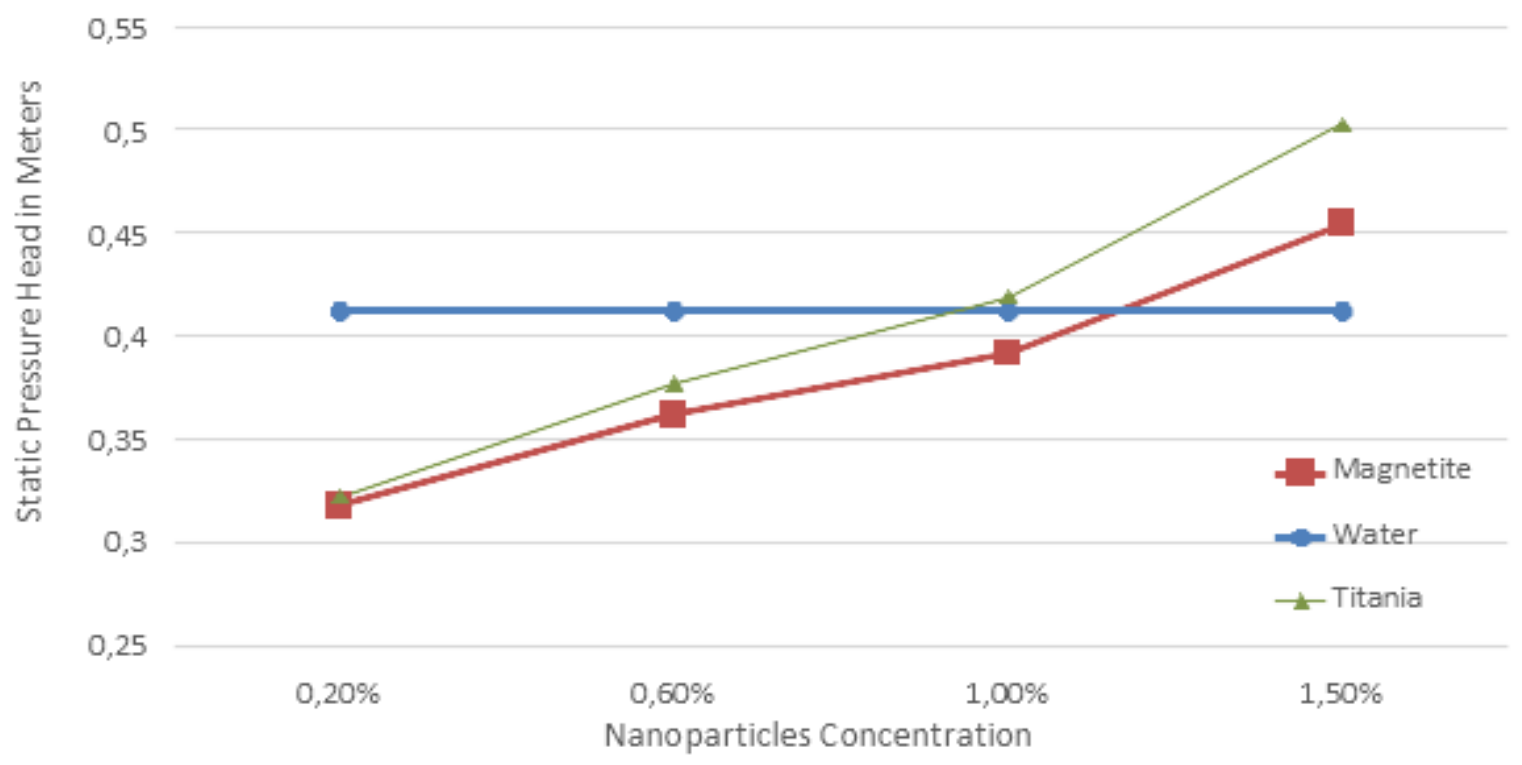

Figura 5: Pressure drop of Magnetite and Titania for Re 18187

Among the nanofluids, graphene presents smaller pressure drop, almost $25 \%$ less than water for 0,0025\% concentration. Besides that, every nanofluids showed a bigger pressure drop than pure water with bigger particles concentration, being the biggest pressure drop in titania at $1,5 \%$ concentration.

The decrease of pressure drop is due to the decrease of viscosity, that is a consequence of less shear stress on pipe wall, resulting in a minor loss of piping energy. [5] suggests decreasing of viscosity is assigned to structural alignment of carbon nanoparticles networks in the beginning of shear. This behavior could result in a minor viscous force. Nevertheless, theses conclusions were took from experimental studies, as presented by [3], but more studies are necessary for right descriptions of theses phenomenons with different kind of nanoparticles and geometries. 


\section{CONCLUSION}

In this study, the influence of particles concentration of three different kind of nanofluids was numerically investigated, having pure water as a reference. The results showed a decrease of pressure drop in nanofluids with low concentration, less than $0,0075 \%$ for graphene and less than $1,00 \%$ for titania and magnetite, for flows with 18187 Re number. For flows with 4583 Re number, pressure drop decrease only for graphene and in concentrations lower than $0,05 \%$, possibly because of a not fully developed flow.

Consequently, its reasonable to predict a decrease of pressure drop in all nanofluids with smaller concentration of particles and fully developed turbulent flows. On the other hand, studies about how particles geometry affect rheology are still inconclusives. Furthermore, nanofluids were not evaluated on nuclear conditions, as flows with high Re numbers or high temperatures, in other words, normal conditions in nuclear reactors [10]. Also, studies about nanofluids stability after long period of time on use or storage are required.

\section{REFERENCE}

1. FOX, R. Introdução À Mecânica Dos Fluidos, ATLAS EDITORA, 2018

2. XUAN, Y.; LI, Q. Heat transfer enhancement of nanofluid, International Journal of Heat and Fluid Flow 21 (2000) 58-64.

3. CHOI, S. U. S.; EASTMAN, J. A.; Enhancing thermal condutivity of fluids with nanoparticles (1995).

4. SADEGHINEZHAD, E.; TOGUN, H; MEHRALI, M; NEJAD, P.S.; LATIBARI, S.T.; ABDULRAZZAQ, T; KAZI, S.N.; METSELAAR, H.S.C. An experimental and numerical investigation of heat transfer enhancement for graphene nanoplatelets nanofluids in turbulent flow conditions, International Journal of Heat and Mass Transfer (2015) 41-51.

5. HALELFADL, S.; MARÉ, T.; ESTELLE, P. Efficiency of carbon nanotubes water based nanofluids as coolants, Experimental Thermal and Fluid Science 53 (2014) 104 - 110. 
6. CARVALHO, D.F. Instalações elevatórias bombas, Universidade Católica Minas Gerais, 1979.

7. Incropera, F. P.; Lavine, A. S.; Bergman, T. L. and DeWitt, D. P. Fundamentals of heat and mass transfer, Wiley (2007)

8. MICROSOFT, Excel Microsoft-User Guide, 2010.

9. CHEN, L.; XIE, H.; YU, W.; LI, Y. Rheological behaviors of nanofluids containing multiwalled carbon nanotube, Journal of Dispersion Science and Technology 32 (2011) 550554.

10.Todreas, Neil E and Kazimi, Mujid S Nuclear Systems Volume I: Thermal Hydraulic Fundamentals, CRC press, (2011) 